\title{
Overhydration and low serum prealbumin predict peritoneal dialysis-related peritonitis in continuous ambulatory peritoneal dialysis patients
}

Quyen Dao Bui Quy ${ }^{1}$, Tuan Pham Ngoc Huy ${ }^{2}$, Loc Nguyen Duc ${ }^{3}$, My Pham Van ${ }^{4}$, Dung Nguyen Huu', Toan Nguyen Duy ${ }^{6,7}$, Tien Tran Viet ${ }^{6,7}$, Quyet Do ${ }^{7}$ and Thang Le Viet ${ }^{6,7^{*}}$ (D)

\begin{abstract}
Background: In this study, we focused on the role of overhydration $(\mathrm{OH})$ and low serum prealbumin concentration in predicting peritonitis in continuous ambulatory peritoneal dialysis (CAPD) patients over a 3-year period.

Methods: We measured serum prealbumin concentration and $\mathrm{OH}$ by body composition monitor in 278 CAPD patients (159 males and 119 females) with a mean age of 46 years and a median peritoneal dialysis (PD) duration of 21 months. Cases of PD-related peritonitis were collected over 3 years.

Results: After the 3-year follow-up, 44 patients were diagnosed with PD-related peritonitis (15.8\%). Low education, serum glucose, prealbumin, and $\mathrm{OH}$ were independent risk factors for predicting peritonitis over 36 months in CAPD patients. Based on the ROC curve model and Kaplan-Meier analysis, we realized that low prealbumin and high $\mathrm{OH}$ were independent predictors of 3-year peritonitis in CAPD patients (Prealbumin: AUC $=0.838$, cut-off value $=32.5 \mathrm{mg} / \mathrm{dL}$, Se=90.9\%, Sp=32.9\%; OH: AUC = 0.851, cut-off value = $1.33 \mathrm{~L}, \mathrm{Se}=79.5 \%, \mathrm{Sp}=85.5 \%$; and logrank test $p<0.001$, respectively).
\end{abstract}

Conclusion: Overhydration and low serum prealbumin were the independent predictors of PD-related peritonitis in CAPD patients.

Keywords: Continuous ambulatory peritoneal dialysis, Overhydration, Serum prealbumin, Peritoneal dialysis,

Peritonitis

\section{Background}

Peritoneal dialysis (PD) is a renal replacement therapy based on infusing a sterile solution into the peritoneal cavity through a catheter, and it provides for the removal of solutes and water using the peritoneal membrane as the exchange surface [1-3]. Infusion and drainage of the

* Correspondence: lethangviet@yahoo.co.uk

${ }^{6}$ Military Hospital 103, Ha Noi, Viet Nam

7 Vietnam Military Medical University, Ha Noi, Viet Nam

Full list of author information is available at the end of the article solution into the peritoneal cavity can be performed in two ways: manually (continuous ambulatory PD) or machine-assisted PD (automated PD) [1, 2].

Peritonitis is a common serious complication of peritoneal dialysis that results in considerable morbidity, mortality, and health care costs [4-6]. Depending on the underlying causative agent, PD-related peritonitis is complicated by relapse in $3-20 \%$ (14\% overall), catheter removal in $10-88 \%$ ( $22 \%$ overall), and permanent HD transfer in $9-74 \%(18 \%$ overall) of cases $[7,8]$. After a single episode of peritonitis, the risks of death due to infection and cardiovascular

C The Author(s). 2020 Open Access This article is licensed under a Creative Commons Attribution 4.0 International License, which permits use, sharing, adaptation, distribution and reproduction in any medium or format, as long as you give appropriate credit to the original author(s) and the source, provide a link to the Creative Commons licence, and indicate if changes were made. The images or other third party material in this article are included in the article's Creative Commons licence, unless indicated otherwise in a credit line to the material. If material is not included in the article's Creative Commons licence and your intended use is not permitted by statutory regulation or exceeds the permitted use, you will need to obtain permission directly from the copyright holder. To view a copy of this licence, visit http://creativecommons.org/licenses/by/4.0/. The Creative Commons Public Domain Dedication waiver (http://creativecommons.org/publicdomain/zero/1.0/) applies to the data made available in this article, unless otherwise stated in a credit line to the data. 
disease are markedly increased in the first month and continue to remain significantly elevated for up to 6 months afterwards [9]. There are many risk factors for peritonitis in PD patients, including low education, malnutrition, insufficient dialysis, catheter-related peritonitis, etc. [10-12].

$\mathrm{PD}$ is the second most common method of renal replacement therapy after maintenance hemodialysis (HD) in Vietnam. Similar to other countries around the world, peritonitis often occurs in patients with peritoneal dialysis. This causes many patients to switch to maintenance hemodialysis. Many studies have shown that overhydration $(\mathrm{OH})$ often complicates the clinical course and is associated with an increased risk of peritonitis in PD patients [13, 14]. Chronic fluid overload is related to an increased risk of cardiovascular morbidity and mortality in peritoneal dialysis patients [15]. Additionally, prealbumin (transthyretin) is a hepatic secretory protein used to assess malnutrition in PD patients, and it is related to inflammation and atherosclerosis. It also has prognostic value for peritonitis and mortality in PD patients [16, 17]. Up to now, there is no research in Vietnam on the roles of excess fluid and nutritional factors in the prognosis of peritonitis in continuous ambulatory PD patients. As a result of the above reasons, we conducted this study to determine the prevalence of peritonitis and the predictive values of $\mathrm{OH}$ and low serum prealbumin for PD-related peritonitis in Vietnamese peritoneal dialysis patients.

\section{Methods}

\section{Study design and setting}

There were 426 patients on continuous ambulatory peritoneal dialysis (PD duration $>2$ months) in the Department of Nephrology, Cho Ray Hospital, Ho Chi Minh City, Vietnam, from February 2014 to February 2017 (36 months). Of these, patients who were younger than 18 years, dropped out from PD within 90 days, or were on long-term hemodialysis or had chronic renal transplant failure before initiating PD, as well as those with acute illness, significant infection, malignancy, hepatitis virus infection, or peritonitis, before collecting data for the study were excluded. The remaining 278 PD patients were provided informed consent before participation in our study. This study was approved by the ethics review committee of the hospital.

The enrolled patients were treated with stable continuous ambulatory peritoneal dialysis (CAPD) using conventional PD solutions (Dianeal 1.5, 2.5\% or $4.25 \%$ dextrose; Baxter Healthcare), and Y-sets and twin-bag systems were utilized in all of the PD patients. All patients underwent physical examinations and full lab investigations, including serum prealbumin, $\mathrm{OH}$, and measurement of 24-h urine volume to determine residual kidney function, $\mathrm{Kt} / \mathrm{V}$, creatinine clearance $(\mathrm{CCr})$, and the peritoneal equilibration test (PET). For the PET, we calculated a $4 \mathrm{~h}$ dialysate-to- plasma ratio of creatinine (D/Pcr). The PET was categorized among 4 levels (H: high; HA: high-average; LA: lowaverage; and L: low), as developed and described by Twardowski in 1987 [18]. OH was measured using a body composition monitor (BCM, Fresenius). We determined cutoff values for $\mathrm{OH}$ and prealbumin based on the $\mathrm{ROC}$ curve model. In our study, we divided education into 2 levels: high and low education. The patients with elementary and junior secondary education were defined as low education. Anemia was defined as $\mathrm{Hb}<130 \mathrm{~g} / \mathrm{L}$ in males and $<120 \mathrm{~g} / \mathrm{L}$ in females according to the WHO (2011).

PD-related peritonitis was diagnosed and noted for 3 continuous follow-up years. PD-related peritonitis was diagnosed based on at least two of the following criteria [19]: (1) abdominal pain or cloudiness of PD effluent; (2) white blood cell count in PD effluent $>100 / \mu \mathrm{L}$ with $>$ $50 \%$ polymorphonuclear leukocytes; and (3) a positive culture from PD effluent.

Serum prealbumin concentration was measured using a quantitative electrochemiluminescence method (ECLIA) at the time of enrollment.

\section{Statistical analyses}

All normally distributed and continuous data are represented as the mean \pm standard deviation and have been analyzed using Student's t-test, one-way analysis of variance, and post hoc Bonferroni comparison. All the nonnormally distributed data are represented as median (25 percentile75 percentile) and have been analyzed using the MannWhitney U test and Kruskal-Wallis test. Categorical data are presented as the frequency with percentage and have been analyzed using the chi-squared test. Cox proportional hazard models was performed to identify the predictor of peritonitis. Receiver operating characteristic (ROC) curves with the area under the curve (AUC) were calculated to predict peritonitis in patients after 3 years' follow-up. Peritonitis prognosis was assessed using Kaplan-Meier analysis and evaluated by the log-rank test. Statistical analysis was performed using the Statistical Package for Social Science (SPSS) version 20.0 (Chicago, IL, USA). A $p$-value $<0.05$ was considered significant.

\section{Results}

Table 1 shows the basic demographics of all study subjects. In our study, the mean age of the entire cohort was $48.61 \pm 13.63$ years. Additionally, $57.2 \%$ of patients were male, $16.9 \%$ of patients had diabetes mellitus (DM), the median duration of PD was 21 months, $22.7 \%$ of patients had low education, $71.9 \%$ of patients had lost residual kidney function, $95.3 \%$ of patients had anemia, and $15.8 \%$ of patients had peritonitis during the 3-year follow-up, with the ratio of positive bacterial cultures being $27.3 \%$ (12/44 patients). 
Table 1 Comparison of demographic and laboratory characteristics of peritonitis and nonperitonitis groups

\begin{tabular}{|c|c|c|c|c|}
\hline Clinical characteristics and laboratory parameters & All patients $(n=278)$ & Peritonitis $(n=44)$ & Nonperitonitis $(n=234)$ & $p$ \\
\hline Age (years) & $48.61 \pm 13.63$ & $54.57 \pm 12.25$ & $47.49 \pm 13.61$ & 0.001 \\
\hline Number of males ( $n, \%)$ & $159(57.2)$ & $25(56.8)$ & $134(57.3)$ & 0.956 \\
\hline PD duration (month) & $21(10-40.25)$ & $18.5(8-37.5)$ & $23(10-41)$ & 0.516 \\
\hline Low education (n, \%) & $63(22.7)$ & $27(61.4)$ & $36(15.4)$ & $<0.001$ \\
\hline Hypertension (n, \%) & $228(82)$ & $36(81.8)$ & $192(82.1)$ & 0.971 \\
\hline Diabetes mellitus (n, \%) & $47(16.9)$ & $23(52.3)$ & $24(10.3)$ & $<0.001$ \\
\hline \multicolumn{5}{|l|}{ BMl } \\
\hline - Mean & $21.16 \pm 2.93$ & $22.15 \pm 3.43$ & $20.97 \pm 2.79$ & 0.036 \\
\hline$-<18.5$ & $46(16.5)$ & $5(11.4)$ & $41(17.5)$ & \\
\hline$-18.5-22.9$ & $168(60.4)$ & $21(47.7)$ & $147(62.8)$ & 0.009 \\
\hline$-\geq 23$ & $64(23)$ & $18(40.9)$ & $46(19.7)$ & \\
\hline - Min - Max & $14.4-33.3$ & $15.4-31.2$ & $14.4-33.3$ & N/A \\
\hline $\mathrm{OH}(\mathrm{L})$ & $1.27 \pm 0.18$ & $1.49 \pm 0.21$ & $1.23 \pm 0.14$ & $<0.001$ \\
\hline$-24 \mathrm{~h}$ urine volume $(\mathrm{ml})$ & $180(130-500)$ & $195(146.25-637.5)$ & $175(128.75-500)$ & 0.12 \\
\hline - Loss of RKF (n, \%) & $200(71.9)$ & $28(63.6)$ & $172(73.5)$ & 0.181 \\
\hline - Preservation of RKF $(n, \%)$ & $78(28.1)$ & $16(36.5)$ & $62(26.5)$ & \\
\hline \multicolumn{5}{|l|}{ PET } \\
\hline - Mean (D4/P) & $0.7 \pm 0.08$ & $0.73 \pm 0.08$ & $0.7 \pm 0.08$ & 0.024 \\
\hline$-H(n, \%)$ & $20(7.2)$ & $6(13.6)$ & $14(6)$ & \\
\hline - HA (n, \%) & $175(62.9)$ & $28(63.6)$ & $147(62.8)$ & 0.236 \\
\hline - LA (n, \%) & $80(28.8)$ & $10(22.7)$ & $70(29.9)$ & \\
\hline$-L(n, \%)$ & $3(1.1)$ & $0(0)$ & $3(1.3)$ & \\
\hline Blood urea (mmol/L) & $19.29 \pm 6.11$ & $19.16 \pm 6.89$ & $19.31 \pm 5.97$ & 0.88 \\
\hline Creatinine $(\mu \mathrm{mol} / \mathrm{L})$ & 772.16 (654.9-955.8) & 738.97 (608.43-946.95) & 778.8 (657.55-961.99) & 0.372 \\
\hline $\mathrm{Kt} / \mathrm{V}$ & $1.98 \pm 0.3$ & $2.00 \pm 0.31$ & $1.97 \pm 0.3$ & 0.597 \\
\hline Total CCr (L/week/1.73m²) & $62.65 \pm 9.3$ & $63.13 \pm 9.57$ & $62.57 \pm 9.27$ & 0.713 \\
\hline \multicolumn{5}{|l|}{ Hemoglobin } \\
\hline - Mean (g/L) & $100.55 \pm 16.9$ & $95.98 \pm 15.06$ & $101.41 \pm 17.12$ & 0.051 \\
\hline - Anemia (n, \%) & $265(95.3)$ & $43(97.7)$ & $222(94.9)$ & 0.41 \\
\hline WBC (g/L) & $6.86 \pm 1.48$ & $6.94 \pm 1.37$ & $6.85 \pm 1.5$ & 0.711 \\
\hline Neutrophils (\%) & $61.38 \pm 8.44$ & $61.29 \pm 10.77$ & $61.39 \pm 7.96$ & 0.94 \\
\hline hs-CRP (mg/L) & $2(1-4)$ & $3.95(2-5.27)$ & $2(1-3.7)$ & $<0.001$ \\
\hline Glucose (mmol/L) & $4.22(3.77-4.83)$ & $4.47(3.94-5.34)$ & $4.16(3.76-4.79)$ & 0.024 \\
\hline Uric acid ( $\mu \mathrm{mol} / \mathrm{L})$ & $414.63 \pm 83.78$ & $427.04 \pm 101.02$ & $412.3 \pm 80.16$ & 0.285 \\
\hline $\mathrm{Na}+(\mathrm{mmol} / \mathrm{L})$ & $136.93 \pm 3.76$ & $136.17 \pm 3.38$ & $137.07 \pm 3.81$ & 0.145 \\
\hline $\mathrm{K}+(\mathrm{mmol} / \mathrm{L})$ & $3.67 \pm 0.78$ & $3.52 \pm 0.58$ & $3.7 \pm 0.81$ & 0.164 \\
\hline $\mathrm{Ca}++(\mathrm{mmol} / \mathrm{L})$ & $2.05 \pm 0.29$ & $2.04 \pm 0.23$ & $2.05 \pm 0.31$ & 0.83 \\
\hline Protein (g/dL) & $6.51 \pm 0.69$ & $6.45 \pm 0.8$ & $6.53 \pm 0.67$ & 0.515 \\
\hline Albumin (g/dL) & $3.69 \pm 0.48$ & $3.36 \pm 0.61$ & $3.75 \pm 0.42$ & $<0.001$ \\
\hline Prealbumin (mg/dL) & $34.35 \pm 8.49$ & $26.34 \pm 5.54$ & $35.86 \pm 8.1$ & $<0.001$ \\
\hline
\end{tabular}

PD Peritoneal Dialysis, BMI Body Mass Index, $O H$ Overhydration, PET Peritoneal Equilibration Test, $H$ High, HA High-Average, LA Low-Average, $L$ Low, WBC White Blood Cell, hs-CRP High-Sensitivity C- Reactive Protein 
Per the results in Table 1 , in the peritonitis group, the average age was older, the proportions of low education and DM were higher, the average $\mathrm{OH}$ and hs-CRP levels were higher, and the serum average albumin and prealbumin concentrations were significantly lower than those in the nonperitonitis group (all $p<0.001$ ).

There were many independent factors significantly associated with peritonitis, including low education, glucose, prealbumin, and $\mathrm{OH}$, based on the results of Cox proportional hazard models with $p<0.05$ (Table 2).

Based on the results of the ROC curve analysis in Fig. 1, there were many factors predictive for peritonitis, with the prealbumin level and $\mathrm{OH}$ having the strongest values (Prealbumin: $\mathrm{AUC}=0.838$, cut-off value $=32.5 \mathrm{mg} / \mathrm{dL}$, $\mathrm{Se}=90.9 \%, \mathrm{Sp}=32.9 \% ; \mathrm{OH}: \mathrm{AUC}=0.851$, cut-off value $=$ $1.33 \mathrm{~L}, \mathrm{Se}=79.5 \%, \mathrm{Sp}=85.5 \%$ ).

The Kaplan-Meier analysis in Fig. 2 shows that patients with high $\mathrm{OH}(\mathrm{OH} \geq 1.33 \mathrm{~L}$ : blue line $)$ exhibit a significantly higher peritonitis rate than those with low $\mathrm{OH}(\mathrm{OH}<1.33 \mathrm{~L}$ : violet line) (log-rank test, $p<0.001)$.

Oppositely, according to the results of Kaplan-Meier analysis in Fig. 3, patients with a low prealbumin level (serum prealbumin $\leq 32.5 \mathrm{mg} / \mathrm{dL}$ : blue line) exhibit a significantly higher peritonitis rate than those with a high serum prealbumin level (serum prealbumin $>32.5 \mathrm{mg}$ / $\mathrm{dL}$ : violet line) (log-rank test, $p<0.001)$.

\section{Discussion}

\section{Prevalence peritonitis}

To determine PD-related peritonitis in the end-stage kidney disease patients undergoing CAPD, we excluded patients who had previous peritonitis. After follow-up for 3 years, the proportion of peritonitis in our study was $15.8 \%$ (Table 1). There have been some reports about the prevalence of PD-related peritonitis. Ye H. et al. [5] conducted a study with $1321 \mathrm{PD}$ patients with a follow-up of 5 years, and the proportion of peritonitis was $28.16 \%$ (372/1321 patients). Furthermore, in the first year of PD initiation, 169 (13\%) patients had experienced episodes of peritonitis, and the proportion of patients with peritonitis fluctuated from
8 to $13 \%$ in the subsequent years. Gadola L. et al. [20] surveyed the rate of peritonitis in $222 \mathrm{PD}$ patients with a follow-up of 6 years, and the results showed 95 patients suffered 1 or more episodes of peritonitis (42.79\%). In a study by Ponce, the proportion of peritonitis in children was $25.45 \%$ with a follow-up of 7 years (125 first episodes of peritonitis in $491 \mathrm{PD}$ patients who were children) [21]. The proportion of peritonitis in our study was lower than that in other studies, because our follow-up time was shorter. Overall, $27.3 \%$ of patients had a positive bacterial culture in our study, which is similar to other study results $[5,21]$.

\section{Relation between peritonitis and some patient characteristics}

In Vietnam, peritoneal dialysis is concentrated only in 2 large cities, Hanoi and Ho Chi Minh City. When being recommended chronic kidney replacement therapy, most patients choose maintenance hemodialysis. Only approximately $20 \%$ of patients choose peritoneal dialysis, because they do not have time to go to hemodialysis centers. When comparing the peritonitis and nonperitonitis groups, we found some patient characteristics related to peritonitis. In the peritonitis group, the average age was older and the proportions of low education and DM were significantly higher than those in the nonperitonitis group $(p<0.001)$ (Table 1). It remains controversial whether older PD patients have a substantially increased risk of peritonitis than their younger counterparts. More recently, retrospective studies have found that older age (more than 65 years) was the only identifiable risk factor associated with peritonitis $[22,23]$. It seems highly probable that touch contamination and bowel dysfunction are important underlying causes of episodes of peritonitis in older PD patients [24]. Diabetes mellitus and low education have been risk factors for PD-related peritonitis in previous studies [24-26]. As diabetes mellitus is regarded a risk factor for infections in general, it seems reasonable to also consider it a risk factor for peritonitis in PD patients [26]. In this study, we found the relationship between peritonitis and overhydration (Tables 1,2$)$. The results of our study were similar to those

Table 2 Adjusted and unadjusted Hazard Ratio and 95\% confidence interval for Cox proportional hazard models predicts peritonitis in continuous ambulatory peritoneal dialysis patients

\begin{tabular}{|c|c|c|c|c|}
\hline Variable & Crude hazard ratio $[95 \% \mathrm{Cl}]$ & $p$-value & $\begin{array}{l}\text { Adjusted hazard } \text { ratio }^{a} \\
{[95 \% \mathrm{Cl}]}\end{array}$ & $p$-value \\
\hline Low education & $3.455[1.655-7.17]$ & 0.001 & $3.357[1.463-7.706]$ & 0.004 \\
\hline $\mathrm{OH}(\mathrm{L})$ & 81.319 [17.685-374.839] & $<0.001$ & 74.112 [10.562-520.033] & $<0.001$ \\
\hline hs-CRP (mg/L) & $1.179[1.016-1.368]$ & 0.03 & $1.168[0.998-1.367]$ & 0.054 \\
\hline Glucose (mmol/L) & $1.214[1.072-1.375]$ & 0.002 & $1.224[1.07-1.401]$ & 0.003 \\
\hline Albumin (g/dL) & $0.612[0.363-1.032]$ & 0.066 & $0.634[0.348-1.156]$ & 0.137 \\
\hline Prealbumin (mg/dL) & $0.848[0.802-0.896]$ & $<0.001$ & $0.847[0.801-0.895]$ & $<0.001$ \\
\hline
\end{tabular}

PD Peritoneal Dialysis, hs-CRP High-Sensitivity C-Reactive Protein, $\mathrm{OH}$ Overhydration

${ }^{a}$ Hazard ratio was adjusted by age, diabetes, BMI, and D4/P 


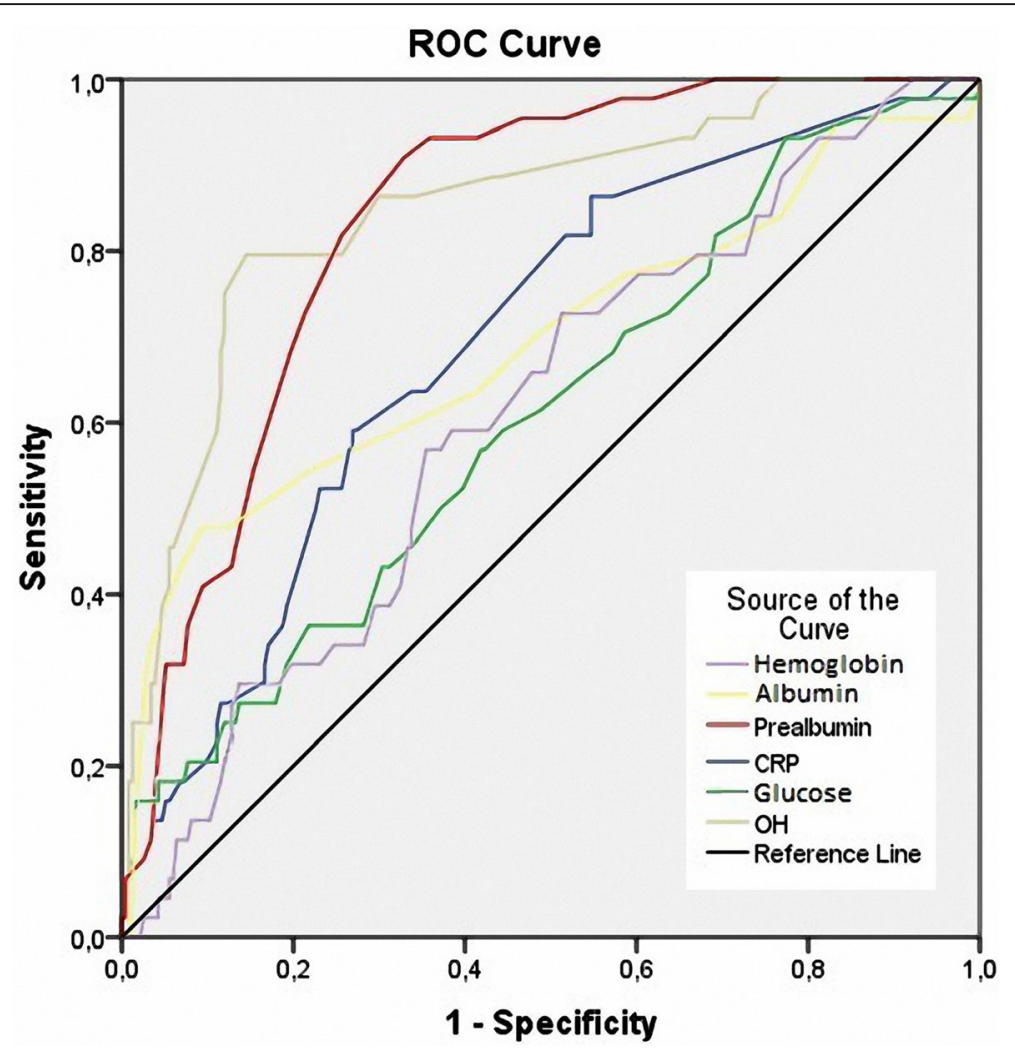

Fig. 1 Receiver operating characteristic (ROC) curves of hemoglobin, glucose, hs-CRP, OH, albumin, and prealbumin for the prediction of peritonitis

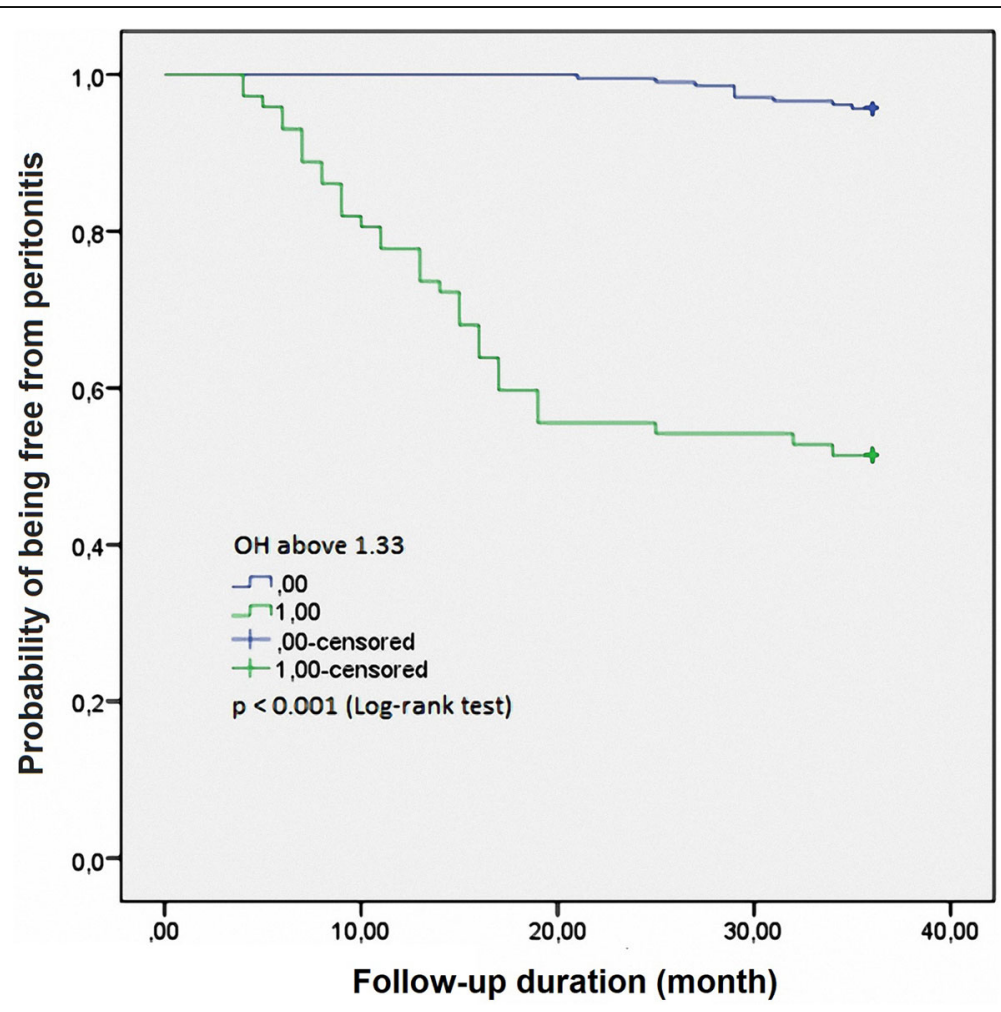

Fig. 2 Kaplan-Meier analysis of peritonitis in 278 continuous ambulatory peritoneal dialysis patients, classified according to $\mathrm{OH}$ level 


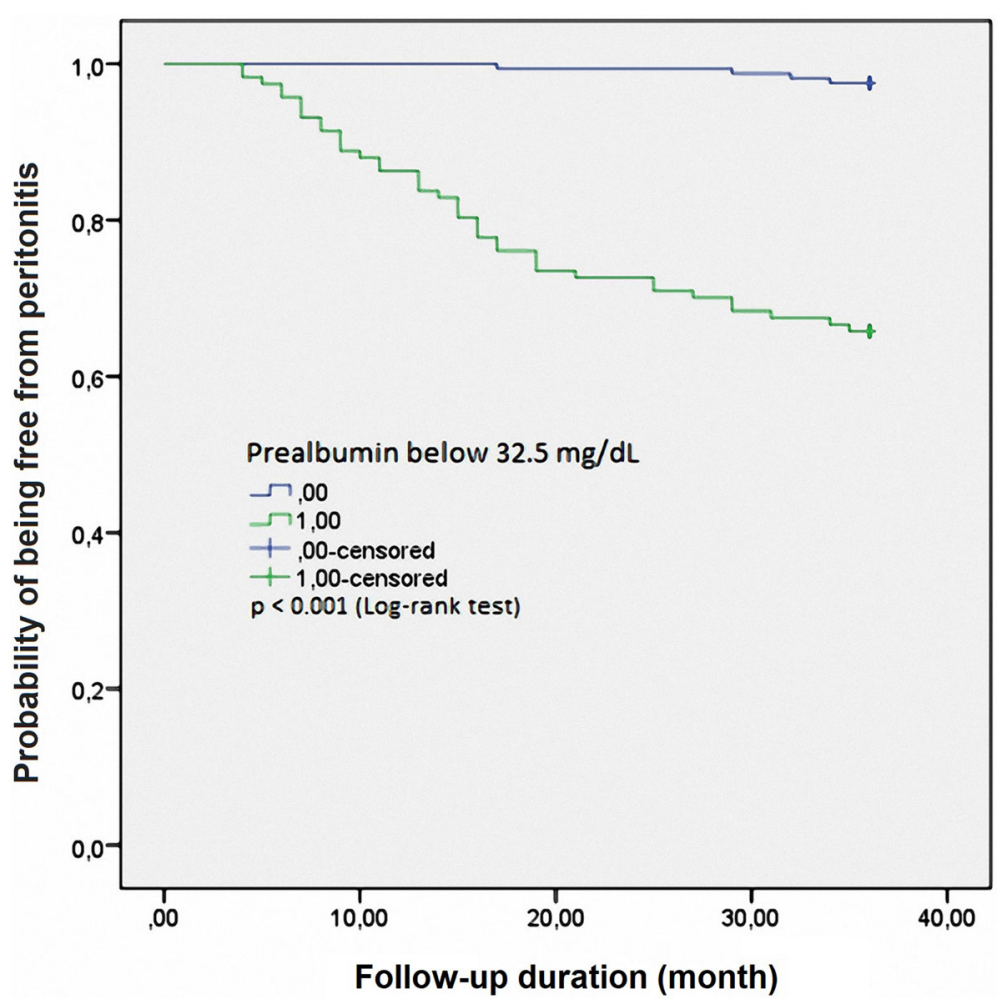

Fig. 3 Kaplan-Meier analysis of peritonitis in 278 continuous ambulatory peritoneal dialysis patients, classified according to serum prealbumin concentration

of others $[13,14]$. The association between $\mathrm{OH}$ and peritonitis maybe by enteric microorganisms [14]. This seems to be reasonable, as there is a trend toward an association between baseline levels of C-reactive protein and PDrelated peritonitis (Tables 1,2 ).

The relationship between peritonitis and malnutrition was also expressed in our study (Tables 1,2 ). The average serum albumin and prealbumin levels in the peritonitis group were significantly lower than those in the nonperitonitis group $(p<0.001)$. Peritoneal dialysis itself might lead to protein-energy wasting due to the continuous glucose absorption from peritoneal dialysis solutions and abdominal fullness induced by the dialysate. The result is a decrease in serum albumin and prealbumin concentrations in patients with peritoneal dialysis [27]. Dong J et al. also confirmed that protein leakage predicted the risk for peritonitis in patients on peritoneal dialysis, and this association remained even after adjustment for systemic inflammation estimated by serum albumin, hs-CRP, and IL-6 [28].

\section{Factors predicting peritonitis}

In this study, we found that there were many independent factors related to peritonitis in CAPD patients, of which prealbumin and $\mathrm{OH}$ are closely related $(p<0.001)$ (Table 2 ). We also found that $\mathrm{OH}$ and serum prealbumin were the independent predictors of peritonitis compared to other factors, such as glucose, serum albumin, and hs-CRP
(AUC of prealbumin was 0.838 and that of $\mathrm{OH}$ was 0.851 , $p<0.001$ ) (Fig. 1). The predictive values, by Kaplan-Meier analysis, for both serum prealbumin and $\mathrm{OH}$ with regard to peritonitis were also evident with a follow-up of 3 years (Figs. 2, 3). There are some previous reports about predictive factors for PD-related peritonitis in CAPD patients [20, 22, 23]. Gadola L. et al. [20] confirmed that a multidisciplinary peritoneal educational program improved peritonitis rates, independently of other risk factors. Okayama $M$. et al. found that aging was an important risk factor for peritoneal dialysis-associated peritonitis [22]. In particular, Kerschbaum J et al. [26] reviewed 415 studies on risk factors for peritonitis in PD patients. From those studies, the author found that the risk factors for peritonitis were divided into two groups: nonmodifiable and modifiable risk factors. Nonmodifiable risk factors are ethnicity, old age, female, cardiovascular comorbidities, DM, underlying renal disease (such as lupus), and loss of residual renal function. Modifiable risk factors are malnutrition, overweight, smoking, comedication with immunosuppressants, depression, and low socioeconomic status. In summary, many risk factors for PD-related peritonitis have been identified in studies of acceptable methodological quality. Overhydration is common among PD patients and related to cardiovascular risk and death [29-31]. Prealbumin levels were an independent and sensitive predictor for mortality in incident PD patients, showing a good 
correlation with nutritional and inflammatory markers $[17,32]$. An association between $\mathrm{OH}$ and the risk of peritoneal infection by enteric germs was reported in a study by Carvalho Fiel D [14]. It has been suggested that persistent edema of the intestinal wall may favor microbial and bacterial endotoxin transmigration, leading to systemic infections (including peritonitis) in some cases [14]. Serum albumin and prealbumin are the measures to evaluate the nutritional status of chronic patients in general, especially in patients receiving peritoneal dialysis. Decreased albumin and prealbumin concentrations associated with peritonitis in peritoneal dialysis patients have been mentioned by several authors [26-28]. It might be hypothesized that hypoalbuminemia (as a result of malnutrition, the inflammatory response, or uremia itself) may lead to a higher susceptibility to infection [26]. Thus, both $\mathrm{OH}$ and serum prealbumin are modifiable risk factors for PD-related peritonitis, which have predictive value for peritonitis in CAPD patients. This result once again confirms the role of $\mathrm{OH}$ and serum prealbumin in predicting outcomes of CAPD patients. From this result, good control of $\mathrm{OH}$ and serum prealbumin is needed to reduce the rate of peritonitis in CAPD patients.

Although our results showed that overhydration and low serum prealbumin were the independent predictors of PD-related peritonitis in CAPD patients, this study still had some limitations. First, we did not determine evidence of all other modifiable and nonmodifiable factors related to peritonitis among PD patients [33]. Second, we were unable to obtain repeated measures of prealbumin and $\mathrm{OH}$ during the 3-year follow-up period. Therefore, we could not determine the "real" association of prealbumin and $\mathrm{OH}$ with the outcome, as well as evaluate the variation of prealbumin and $\mathrm{OH}$ in peritoneal dialysis patients over the follow-up time.

\section{Conclusion}

In conclusion, overhydration and low serum prealbumin were the independent predictors of PD-related peritonitis in CAPD patients.

\section{Abbreviations}

$\mathrm{OH}$ : Overhydration; CAPD: Continuous ambulatory peritoneal dialysis; PD: Peritoneal dialysis; CCr: Creatinine clearance; ROC: Receiver operating characteristic; DM: Diabetes mellitus; AUC: Area under the curve

\section{Acknowledgments}

In this study, we had been strongly supported by our local hospital and university to complete our research.

\section{Declarations}

Not applicable.

\section{Authors' contributions}

Research idea and study design: QĐBQ, TPNH. Data acquisition: LND, DNH. Data analysis/interpretation: MPV. Statistical analysis: TND. Supervision or mentorship: TTV, QĐ, TLV. All authors have read and approved the manuscript.
Funding

We did not receive any funding to conduct this research.

\section{Availability of data and materials}

The datasets used and/or analyzed during the current study are available from the corresponding author on reasonable request.

Ethics approval and consent to participate

This study was approved by the Ethical Committee of Vietnam Military Medical University (No. 1238/QĐ-HVQY). Informed consent was obtained from all the participants.

Consent for publication

Not Applicable.

\section{Competing interests}

The authors declare that they have no competing interests.

\section{Author details}

${ }^{1}$ Cho Ray Hospital, Ho Chi Minh, Viet Nam. ${ }^{2}$ Trung Vuong Hospital, Ho Chi Minh, Viet Nam. ${ }^{3}$ An Sinh Hospital, Ho Chi Minh, Viet Nam. ${ }^{4}$ University of Medicine Pham Ngoc Thach, Ho Chi Minh, Viet Nam. ${ }^{5}$ Bach Mai Hospital, Ha Noi, Viet Nam. ${ }^{6}$ Military Hospital 103, Ha Noi, Viet Nam. ${ }^{7}$ Vietnam Military Medical University, Ha Noi, Viet Nam.

Received: 22 July 2020 Accepted: 19 November 2020

Published online: 25 November 2020

\section{References}

1. Andreoli MCC, Totoli C. Peritoneal Dialysis. Rev Assoc Méd Bras. 2020;66: s37-44.

2. Mehrotra R, Devuyst O, Davies SJ, Johnson DW. The current state of peritoneal dialysis. J Am Soc Nephrol. 2016:27(11):3238-52

3. Krediet R, Abrahams A, De Fijter C, Betjes M, Boer W, Van Jaarsveld B, et al. The truth on current peritoneal dialysis: state of the art. Neth J Med. 2017: 75(5):179-89.

4. Cho Y, Johnson DW. Peritoneal dialysis-related peritonitis: towards improving evidence, practices, and outcomes. Am J Kidney Dis. 2014;64(2):278-89.

5. Ye H, Zhou Q, Fan L, Guo Q, Mao H, Huang F, et al. The impact of peritoneal dialysis-related peritonitis on mortality in peritoneal dialysis patients. BMC Nephrol. 2017;18(1):186

6. Liakopoulos V, Nikitidou O, Kalathas T, Roumeliotis S, Salmas M, Eleftheriadis T. Peritoneal dialysis-related infections recommendations: 2016 update. What is new? Int Urol Nephrol. 2017;49(12):2177-84.

7. Szeto C-C, Wong TY-H, Chow K-M, Leung C-B, Li PK-T. The clinical course of culture-negative peritonitis complicating peritoneal dialysis. Am J Kidney Dis. 2003;42(3):567-74.

8. Ghali JR, Bannister KM, Brown FG, Rosman JB, Wiggins K, Johnson DW, et al. Microbiology and outcomes of peritonitis in Australian peritoneal dialysis patients. Perit Dial Int. 2011;31(6):651-62.

9. Boudville N, Kemp A, Clayton P, Lim W, Badve SV, Hawley CM, et al. Recent peritonitis associates with mortality among patients treated with peritoneal dialysis. J Am Soc Nephrol. 2012;23(8):1398-405.

10. Segal JH, Messana JM. Prevention of peritonitis in peritoneal dialysis. Seminars in dialysis; 2013: Wiley Online Library.

11. Bolton L. Preventing peritoneal dialysis infections. Wounds. 2019;31(6):163.

12. Hu S, Ming P, Qureshi AR, Lindholm B, Bo Y, Yang H. Peritonitis: episode sequence, microbiological variation, risk factors and clinical outcomes in a North China peritoneal dialysis center. Kidney Blood Press Res. 2018:43(5):1573-84.

13. Guo Q, Lin J, Li J, Yi C, Mao H, Yang X, et al. The effect of fluid overload on clinical outcome in southern chinese patients undergoing continuous ambulatory peritoneal dialysis. Perit Dial Int. 2015;35(7):691-702.

14. Carvalho DF, Pérez-Fontán M, López Al, Bravo LG-B, García LG, García TF, et al. Persistent overhydration is associated with a significant risk of peritoneal infection by enteric pathogens in patients treated with peritoneal dialysis. Nefrologia. 2019:39(6):638-45.

15. Cheng LT, Gao YL, Qin C, et al. Volume overhydration is related to endothelial dysfunction in continuous ambulatory peritoneal dialysis patients. Perit Dial Int. 2008 Jul-Aug;28(4):397-402. 
16. Fan X, Huang R, Wang J, Ye H, Guo Q, Yi C, et al. Risk factors for the first episode of peritonitis in southern Chinese continuous ambulatory peritoneal dialysis patients. PLoS One. 2014;9(9):e107485.

17. Lee KH, Cho J-H, Kwon O, Kim S-U, Kim RH, Cho YW, et al. Low prealbumin levels are independently associated with higher mortality in patients on peritoneal dialysis. Kidney Res Clin Pract. 2016;35(3):169-75.

18. La Milia V. Peritoneal transport testing. J Nephrol. 2010;23(6):633-47.

19. Li PK-T, Szeto CC, Piraino B, Bernardini J, Figueiredo AE, Gupta A, et al. Peritoneal dialysis-related infections recommendations: 2010 update. Perit Dial Int. 2010;30(4):393-423.

20. Gadola L, Poggi C, Dominguez P, Poggio MV, Lungo E, Cardozo C. Risk factors and prevention of peritoneal dialysis-related peritonitis. Perit Dial Int. 2019:39(2):119-25.

21. Ponce D, De Moraes TP, Pecoits-Filho R, Figueiredo AE, Barretti P. Peritonitis in children on chronic peritoneal dialysis: the experience of a large National Pediatric Cohort. Blood Purif. 2018;45(1-3):118-25.

22. Okayama M, Inoue T, Nodaira Y, et al. Aging is an important risk factor for peritoneal dialysis-associated peritonitis. Adv Perit Dial. 2012;28:50-4.

23. Hsieh Y-P, Chang C-C, Wen Y-K, Chiu P-F, Yang Y. Predictors of peritonitis and the impact of peritonitis on clinical outcomes of continuous ambulatory peritoneal dialysis patients in Taiwan-10 years' experience in a single center. Perit Dial Int. 2014:34(1):85-94.

24. Tsai C-C, Lee J-J, Liu T-P, Ko W-C, Wu C-J, Pan C-F, et al. Effects of age and diabetes mellitus on clinical outcomes in patients with peritoneal dialysisrelated peritonitis. Surg Infect. 2013;14(6):540-6.

25. Barretti P, Moraes TM, Camargo CH, Caramori JC, Mondelli AL, Montelli AC, et al. Peritoneal dialysis-related peritonitis due to Staphylococcus aureus: a single-center experience over 15 years. PLoS One. 2012;7(2):e31780.

26. Kerschbaum J, König P, Rudnicki M. Risk factors associated with peritonealdialysis-related peritonitis. Int J Nephrol. 2012;2012:483250.

27. Dalrymple LS, Johansen $\mathrm{KL}$, Chertow GM, Grimes B, Anand S, McCulloch CE, et al. Longitudinal measures of serum albumin and prealbumin concentrations in incident dialysis patients: the comprehensive dialysis study. J Ren Nutr. 2013;23(2):91-7.

28. Dong J, Chen Y, Luo S, Xu R, Xu Y. Peritoneal protein leakage, systemic inflammation, and peritonitis risk in patients on peritoneal dialysis. Perit Dial Int. 2013:33(3):273-9.

29. Aguiar PV, Santos O, Teixeira L, Silva F, Azevedo P, Vidinha J, et al. Overhydration prevalence in peritoneal dialysis-a 2 year longitudinal analysis. Nefrología (English Edition). 2015;35(2):189-96.

30. Shu Y, Liu J, Zeng X, Hong HG, Li Y, Zhong H, et al. The effect of overhydration on mortality and technique failure among peritoneal dialysis patients: a systematic review and meta-analysis. Blood Purif. 2018;46(4):350-8.

31. Oei E, Paudel K, Visser A, Finney H, Fan SL. Is overhydration in peritoneal dialysis patients associated with cardiac mortality that might be reversible? World J Nephrol. 2016:5(5):448.

32. Mittman N, Avram MM, Oo KK, Chattopadhyay J. Serum prealbumin predicts survival in hemodialysis and peritoneal dialysis: 10 years of prospective observation. Am J Kidney Dis. 2001;38(6):1358-64.

33. Kerschbaum J, König P, Rudnicki M. Risk factors associated with peritonealdialysis-related peritonitis. Int J Nephrol. 2012;2012, Article ID 483250:11. https://doi.org/10.1155/2012/483250.

\section{Publisher's Note}

Springer Nature remains neutral with regard to jurisdictional claims in published maps and institutional affiliations.

Ready to submit your research? Choose BMC and benefit from:

- fast, convenient online submission

- thorough peer review by experienced researchers in your field

- rapid publication on acceptance

- support for research data, including large and complex data types

- gold Open Access which fosters wider collaboration and increased citations

- maximum visibility for your research: over $100 \mathrm{M}$ website views per year

At $\mathrm{BMC}$, research is always in progress.

Learn more biomedcentral.com/submissions 